\title{
Reciprocating wear test of dental composites: effect on the antagonist
}

\author{
A. Ramalho ${ }^{\mathrm{a}, 1}, \mathrm{P}$. Vale Antunes ${ }^{\mathrm{b}, *}$ \\ ${ }^{a}$ ICEMS, Departamento de Engenharia Mecânica, Faculdade de Ciências e Tecnologia da Universidade de Coimbra, \\ Pinhal de Marrocos, 3030 Coimbra, Portugal \\ ${ }^{\mathrm{b}}$ Escola Superior de Tecnologia, Instituto Politécnico de Castelo Branco, Av. do Empresário, 6000-767 Castelo Branco, Portugal
}

Received 10 September 2004; received in revised form 5 January 2005; accepted 7 February 2005

Available online 10 May 2005

\begin{abstract}
Resin composites were first introduced as anterior restorative materials, but are more and more used in posterior teeth, as amalgam replacements. Nowadays the so-called 'condensable' composites are frequently used in posterior teeth. These materials are subjected to high values of contact and mastigatory loads, loading rates and sliding distances. In such contact conditions, wear is the major failure mode of dental composites. Wear of dental composites includes such diverse phenomena as adhesion, abrasion and fatigue. These mechanisms may operate either alone or in combination.

Most of the performed studies involve commercial composite materials and focus on the effect of curing time, and their reflection on the abrasive wear behavior. The wear compatibility of both materials in contact should be one of the concerns of the wear studies. However, the majority of studies do not consider the wear produced on the antagonist material. The present study aims to the understanding of the behavior of commercial composites under reciprocating contact. For the tests, a glass ball was used as opponent. At the end of each test, the wear volume was calculated on both contact materials: the composite and the glass counterface. The removal mechanisms involved in the wear process were discussed taking into account SEM observations of the contact surfaces.
\end{abstract}

(C) 2005 Elsevier B.V. All rights reserved.

Keywords: Dental composites; Wear; Biomaterials; Antagonist wear

\section{Introduction}

During the past decade not only clinicians, but also patients have developed an interest in posterior composite resins. This grown interest has resulted from a desire for esthetics restorations, and also from the amalgam metal character and toxicity. The demand for restorations with a natural appearance in the posterior region and the controversy as to the mercury action on amalgam, although it still has excellent mechanical properties, have attracted researchers to focus on the improvement of the resin composites in order to be applied in posterior teeth. To reach this objective it is essential to understand the

\footnotetext{
* Corresponding author. Tel.: +351 272339 300; fax: +351 272339399.

E-mail addresses: amilcar.ramalho@dem.uc.pt (A. Ramalho), pedrov@est.ipcb.pt (P.V. Antunes).

1 Tel.: +351 239790 700; fax: +351239790701.
}

mechanisms operating in that special environment that is the mouth.

The more reliable way to validate the behavior of the composite materials is doing in vivo studies. These are long time studies, time consuming, and often involving a small number of patients; therefore it is very difficult to extract results likely to apply to the general public. Due to these difficulties, in vitro studies seem to be a good alternative. The first problem is to validate the results attained via in vitro studies with the ones executed in vivo. This correlation is very complicated as there are no standards for some mechanical characterization of these composites, namely for abrasion tests [1]. There are a large number of variables involved in the in vitro studies, and the type of tests used in experimental approach varies greatly from investigating team [1-18]. To understand the multiplicity of approaches about the subject, a summary of the most important variables was done. In a considerable number of recent studies, the approaches are not unanimous, namely: on 
the geometry and nature of the materials used for the tests, on the abrasive solutions, on the type of contact/movement and on the way used to evaluate the wear.

Among the published studies, large differences can be observed on the contact conditions, counterface material and abrasive agent [1-18]. Concerning the antagonist material, steels $[2,6,7,14,16,17]$ and enamel $[1,3-5,8]$ are the most tested ones. However, some studies use polymers $[9,18]$ or ceramics $[10,13]$ and one of them uses titanium as antagonist [15]. The existence or non-existence of abrasive particles on the contact is another parameter that varies in the tests. The parameters in which the studies are agreed are the type of contact geometry (plane-sphere) and the type of wear measurement (depth of the wear transversal profile). Most of the studies are based on experiments with simple movements, unidirectional or reciprocate. However, some works try to use a contact with complex movement more similar to what happens in the mouth, using cycles that involve impact rotation and contra-rotation or cycles with different loads and paths to attain different types of wear.

The use of biological materials, either in the abrasive slurries or as one of the contacting materials could be another problem because it is difficult to guarantee minimal control in shape, dimension and hardness; therefore the reproducibility of the test conditions could be a difficult task. Most of published studies aim to investigate the wear of the material composites, but the wear of the opponent body is not considered. Knowing the wear resistance of the material in study is a key factor in materials development, but it is also very important to know how and how much the composite wears the antagonist material, natural tooth, restorative or prosthetic material. In the gathered studies only five of them evaluate the antagonist wear $[1,3,4,14,15]$.

Thus, and after considering all these aspects, the conditions for this present work were chosen. The geometry of the contact was plane-sphere, with reciprocating motion and inorganic slurry. The evaluation of the damage on both composite and the antagonist in what concerns the volume removed during the process was also considered.

The aim of the present work is to study the effect of the abrasive slurry in a contact plane-sphere between dental composites and glass spheres.

For this study, six commercial resin composites, suitable for posterior restorations, were selected. One amalgam was included in the study for the purpose of comparison.

\section{Experimental procedures}

\subsection{Materials and specimens}

Six commercial composite resins were selected for the present study. The commercial trade names are omitted, to avoid commercial references. The composites are therefore referenced by the capital letters A, B, C, D, E and F. Information about the matrix composition and type of reinforcement filler, dimension of particles and volume fraction are given elsewhere [19]. For comparative purposes, a few samples of amalgam with identical geometry were prepared with Kerr ${ }^{\circledR}$ Automix equipment. The amalgam is composed of spherical particles and its constituents are: $\mathrm{Ag}, 34 \% ; \mathrm{Hg}, 42.5 \% ; \mathrm{Cu}$, $7.5 \%$ and $\mathrm{Sn}, 16 \%$.

Fig. 1 presents the morphology of the condensable composite materials used in the study. The images were taken by SEM and the dimension of the reinforcing particles can be seen. In terms of weight fraction of the reinforcement particles their values range from 74 to $82 \%$. Composites A, B, F and $\mathrm{D}$ have a distribution of particles with very similar sizes, while composites $\mathrm{C}$ and $\mathrm{E}$ have particles of very different sizes. The average dimension of the reinforcement particles is $0.6 \mu \mathrm{m}$ for composites $\mathrm{A}, \mathrm{B}, \mathrm{F} ; 0.7 \mu \mathrm{m}$ for composite $\mathrm{D}$ and a mixture of different size particles for composite $\mathrm{E}$, Table 1.

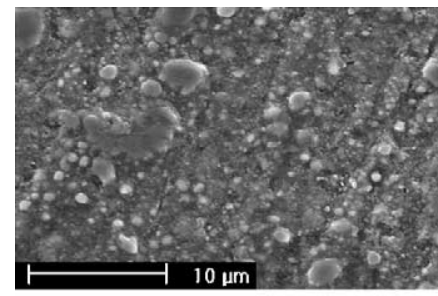

(A)

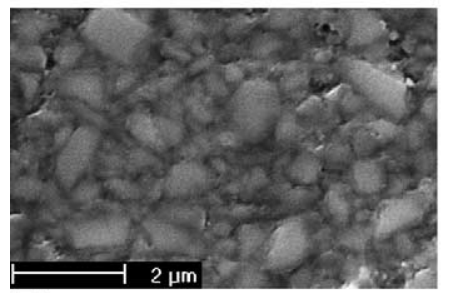

(D)

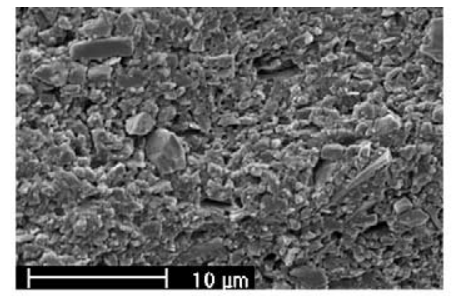

(B)

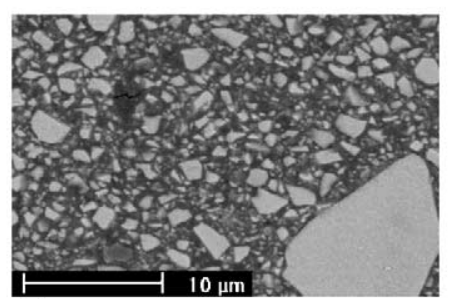

(E)

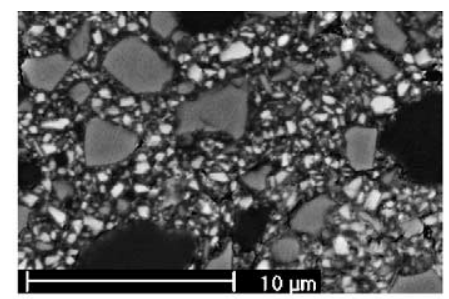

(C)

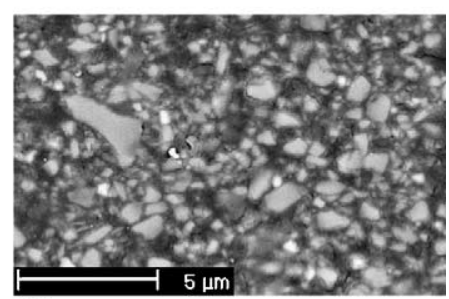

(F)

Fig. 1. Morphology of the composite materials observed by SEM. 
Table 1

Composition of resin composite matrixes used in this work: type, dimension and fraction of the reinforcement filler particles

\begin{tabular}{|c|c|c|c|c|}
\hline \multirow[t]{2}{*}{ Composite designation } & \multirow[t]{2}{*}{ Matrix } & \multicolumn{3}{|l|}{ Reinforcement filler } \\
\hline & & Type & Dimension $(\mu \mathrm{m})$ & Fraction $(\%)$ \\
\hline \multirow[t]{3}{*}{ A } & TEGDMA & & & \\
\hline & Bis-EMA & Zirconia/silica & 0.6 & 61 volume \\
\hline & UDMA & & & \\
\hline B & Bis-GMA & Barium glass & 0.6 & 79 weight \\
\hline \multirow[t]{3}{*}{$\mathrm{C}$} & TEGDMA & & & \\
\hline & (a) & Barium glass & 2 & 80 weight \\
\hline & (b) & Strontium glass & & \\
\hline D & $\begin{array}{l}\text { TEGDMA } \\
\text { (b) }\end{array}$ & Barium glass & 0.7 & 78 weight \\
\hline $\mathrm{E}$ & $\begin{array}{l}\text { Urethane modified } \\
\text { Bis-GMA }\end{array}$ & $\begin{array}{l}\text { Barium/silica } \\
\text { glass }\end{array}$ & $\begin{array}{l}\text { Mixture of different } \\
\text { size particles }\end{array}$ & 81.5 weight \\
\hline \multirow[t]{3}{*}{$\mathrm{F}$} & TEGDMA & & & \\
\hline & Bis-GMA & $\begin{array}{l}\text { Strontıum/barıum } \\
\text { Silica }\end{array}$ & 0.6 & 74 weight \\
\hline & Bis-EMA & & & \\
\hline
\end{tabular}

Bis-GMA: bisphenol diglycidylmethacrylate; UDMA: urethane dimethacrylate; Bis-EMA: bisphenol A polyethylene glycol diether dimenthacrylate; TEGDMA: tri[ethylene glycol] dimethacrylate. (a) Bisphenol A diglycidylurethacrylate and (b) ethoxylate bisphenol A dimethacrylate.

An aluminum mould was used to produce disc-shape specimens of composite and amalgam, $10 \mathrm{~mm}$ in diameter and $2 \mathrm{~mm}$ thick. The mould was placed on a transparency film, resting on a glass, filled manually with a slight excess of resin composite and covered in the same manner as the bottom face. Before curing, the composite samples were compacted manually by applying light finger pressure on the upper glass. A Kerr $^{\circledR}$ polymerisation unit, the Optilux 501 , was used to perform these tasks. The output wavelength range of the curing light varies from 400 to $510 \mathrm{~nm}$, and minimal light intensity $850 \mathrm{~mW} / \mathrm{cm}^{2}$, using an $8 \mathrm{~mm}$ curved turbo light guide (information taken from the technical description of the manufacturer). Curing time was $40 \mathrm{~s}$. The tip of the light guide was placed in contact with the upper glass in order to ensure curing efficiency. The polymerisation unit ensures a curing depth greater than the thickness of the specimens.

\subsection{Wear tests}

The wear test selected was of the reciprocating type, with geometry plane-sphere. This type of test was used for several reasons: first, due to similitude with the natural movement occurred in the mouth; secondly previous experiences in unidirectional tests, namely ball-cratering [19], and finally because of the possibilities of the variations in the amplitude of movement and contact conditions, specifically environment solutions. The possibility of evaluating the wear of both materials in contact is also an important advantage of this type of tests.

In order to evaluate the effect of a third body in the wear of the materials in contact, tests were done, either with artificial saliva or with an abrasive solution. Both types of tests use as antagonist body glass balls with a radius of $5 \mathrm{~mm}$. This value was selected to be similar to the curvature radius of molar teeth.
The reciprocating test was performed to determine the wear resistance of the chosen materials. This technique consists of a sphere in reciprocating motion, in sliding contact with a flat specimen of composite material. The sphere is kept in permanent contact with the horizontal wear surface of the stationary specimen. A normal load of $5 \mathrm{~N}$ was applied to the ball, and the oscillatory movement was set a stroke length of $2 \mathrm{~mm}$ and frequency of $2.9 \mathrm{~Hz}$. During the chewing process of human beings, the magnitude of mastigatory force in the oral cavity ranges from 3 to $36 \mathrm{~N} \mathrm{[20].} \mathrm{As} \mathrm{in} \mathrm{the} \mathrm{current} \mathrm{study,}$ theoretically the surfaces interact by point contact; the normal load was fixed near the minimum referred values. The duration of the tests differ, artificial saliva tests had 10,500 cycles while the ones with abrasive slurry only had 2,600 cycles.

The tests conditions were very similar for both types of test, excepting the number of cycles and the test environment. Table 2, presents the characteristics of the two wear tests.

Respecting the number of cycles, for the abrasive tests, the duration is smaller due to the fact that the associated damage is grater. The duration of 2,600 allows the system to create sufficient wear volume in order to be visualized and measured on both the composites and the counterbody.

After testing, the specimens were scanned by Roddenstock RM 600 laser stylus. The scanning done to all of the flat specimens were transversal to the sliding direction, the distance between profiles ranged from 20 to $30 \mu \mathrm{m}$, depending of the length of the wear scar. The areas of the 2-D profiles were integrated along the length of the wear mark allowing the determination of the volume removed by wear of composite dental material. The wear volume of the counterbody, glass sphere, has a spherical-caps shape and the diameter of their surface was measured in two orthogonal directions: the direction of motion and the direction perpendicular to it. The average values of crater radius, $r$, as well as the sphere radius, $R$, were then used to calculate the depth, $h$, and volume, $V$, 
Table 2

Characterizations of the two types of wear tests

\begin{tabular}{lll}
\hline Type of test & Abrasive slurry & Saliva \\
\hline Stroke length $(\mathrm{mm})$ & 2 & 2 \\
Frequency $(\mathrm{Hz})$ & 2.9 & 2.9 \\
Test duration (cycles) & 2,600 & 10,500 \\
Normal load $(\mathrm{N})$ & 5 & 5 \\
Antagonist body & $\phi=10 \mathrm{~mm}$, glass ball & $\phi=10 \mathrm{~mm}$, glass ball \\
Solution & Aqueous suspension of $0.35 \mathrm{~g}$ of glass micro-spheres & 0.7 and $1.2 \mathrm{~g} / \mathrm{l}$ of $\mathrm{NaCl}$ and $\mathrm{KCl}$, respectively, in distillated water \\
& $(\phi=4 \mu \mathrm{m})$ per ml of distilled water & \\
\hline
\end{tabular}

of removed material, using suitable equations well described elsewhere [19].

The surface of the wear marks was examined by SEM. All of the tested specimens were sputter-coated with gold in order to allow a better observation. The images were attained with secondary and backscattered electrons to allow seeing the dimension and distribution of the particles and identifying the wear mechanisms occurred in the tests.

\section{Results and discussion}

In the reciprocating test with artificial saliva different amounts of wear were generated in the glass balls by the amalgam and the various composite tested (Fig. 2, negative part of the graphic). The tests of the glass ball against the amalgam generate almost no wear mark in the sphere and it was impossible to measure the scar dimension. In descending order of volume, the amalgam was the restoration material that produces minimal wear in the antagonist body followed by composite E, F, D, B, C and A. In what concerns, the wear volumes of restorative materials, composite $\mathrm{F}$ has the smallest wear followed by amalgam and composites E, D, C, A and B (Fig. 2, positive values of wear volume).

Fig. 3 represents the same type of graphic but now for the reciprocating test with abrasive slurry. The value of the wear volume of the amalgam is very small, $2.95 \times 10^{-4} \mathrm{~mm}^{3}$,

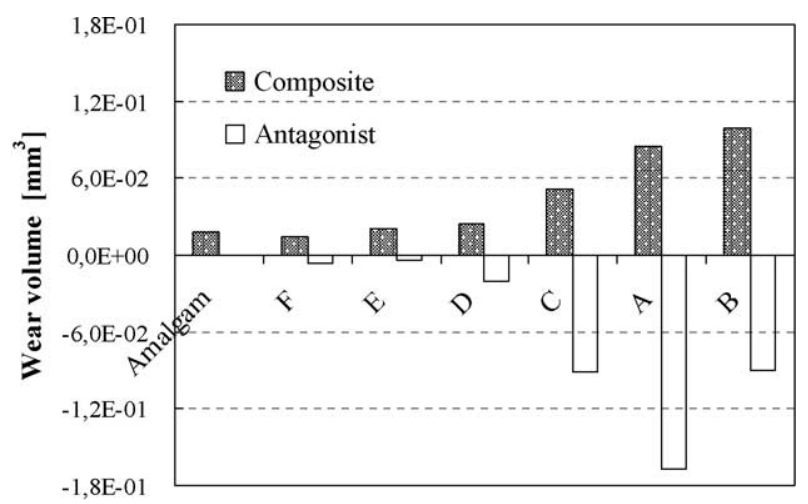

Fig. 2. Wear volumes of the restorative materials and the antagonist body, for the reciprocating test with artificial saliva.

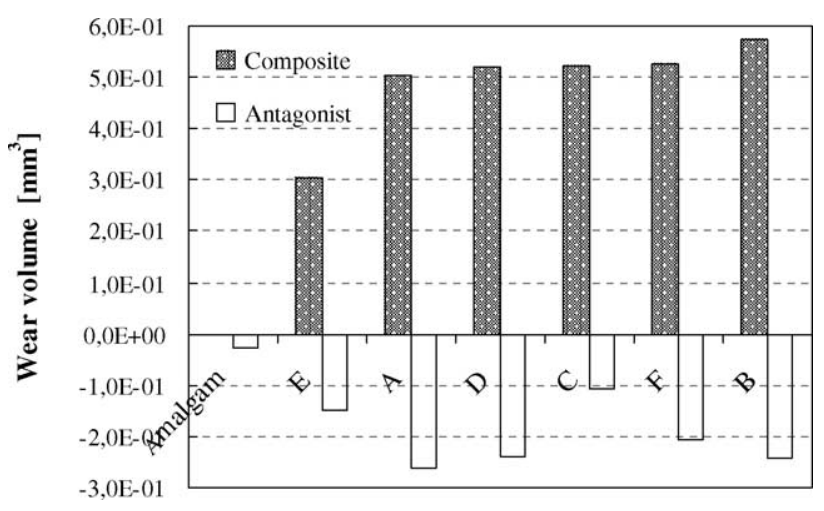

Fig. 3. Wear volumes of the restorative materials and the antagonist body, for the reciprocating test with abrasive slurry.

when compared with the composites, which do not differ very much. After amalgam the wear volumes of the composites are in increasing order as follows: E, A, D, C, F and B.

Although the number of cycles of this test is smaller than the test with saliva, the wear volumes of the composites are greater (Fig. 4).

Fig. 5 represents the wear volume of the antagonist glass sphere. For all the materials the wear volumes are greater in the test with abrasive slurry except for composite C. Comparing the tests with abrasive the difference in wear volume of the different composite materials is small. However, for tests with saliva composites $\mathrm{E}, \mathrm{F}$ and $\mathrm{D}$ perform significantly better than composites A, B and C.

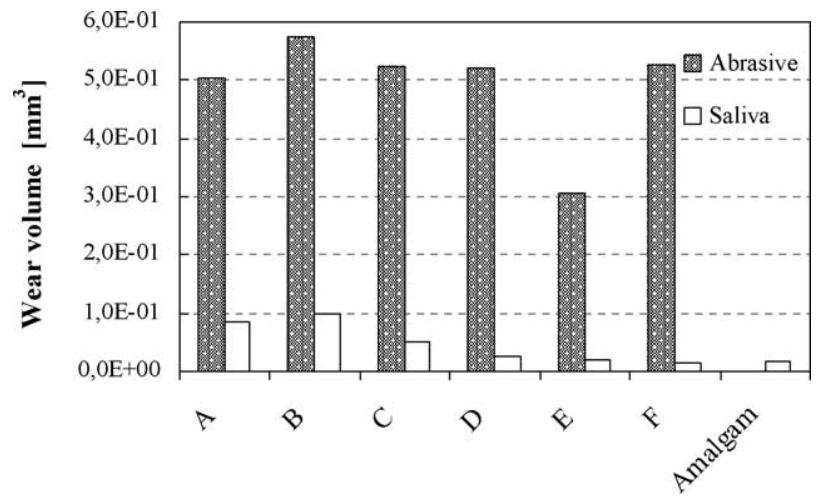

Fig. 4. Comparison of wear volumes of the restorative materials for the reciprocating test with: abrasive slurry and artificial saliva. 


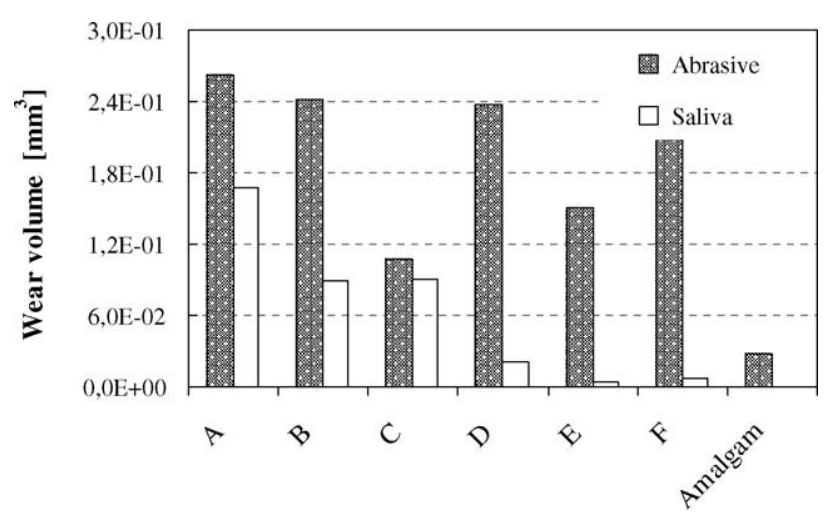

Fig. 5. Wear volumes of the antagonist body for the reciprocating test with: abrasive slurry and artificial saliva.

For the abrasive test, and considering previous studies done [21], a linear relation between the wear volume of restorative materials and their hardness fit the experimental results very well. Fig. 6a represents the hardness of the material as a function of the wear resistance. Here the only composite that does not follow the tendency line is composite E. This may be due not directly to its hardness, but to its microstructure. Composite $\mathrm{E}$ is constituted by sub-micrometric particles and also includes particles of around $40 \mu \mathrm{m}$, thus influencing its behavior, especially in the abrasive tests. For the rest of the tested materials, it shows that increasing values of hardness lead to smaller values of wear.

As observed in Fig. $6 \mathrm{~b}$ tests with saliva also reveal the same tendency. However, Composites A and F do not fit the same linear relation. From the comparison of the two wear tests, the influence of the hardness in the wear resistance of the composites is much higher in the tests with saliva that relation agrees with Archard equation [22]. The slope of the tendency curves is 0.1362 for the saliva and only 0.0005 for the abrasive tests, thus the hardness is more important to enhance wear resistance for contacts without abrasive particles.

Fig. 7 represents the wear resistance of the composites plotted against the wear resistance of the antagonist. For tests with abrasive slurry no direct relationship could be established between the two values (Fig. 7a). However, in the case of the saliva (Fig. 7b), there is a clear relation between the two parameters; a small value of wear composite volume corresponds to a small value of the antagonist body. The different behavior observed in the two types of tests depends on the contact conditions that occur in each one. For the tests with artificial saliva, the contact occurs without abrasive particles, so the area of contact was governed by the wear amount that arises in the softer material (composite). However, when particles are introduced in the contact, the wear in the antagonist is more dependent on the modes of the abrasive particles are instantaneously attached by the composite.

The morphology of the composites wear scars was observed by SEM after the wear tests. To improve the microscope observation, the tested specimens were sputter-coated with gold.

For the test with abrasive (Fig. 8a), hard abrasive particles rest trapped between the contacting surfaces leading to large and deep scratches. In the wear tests with saliva, the surfaces present fewer scratches and the particles are worn along with matrix (Fig. 8b). For each type of tests, the surfaces of the different tested materials do not vary very much.

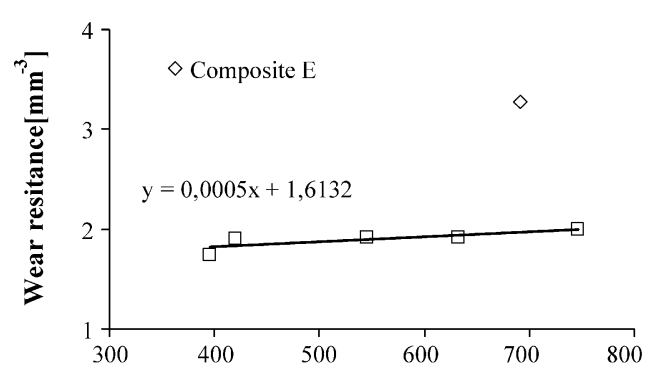

(a)

Hardness [MPa]

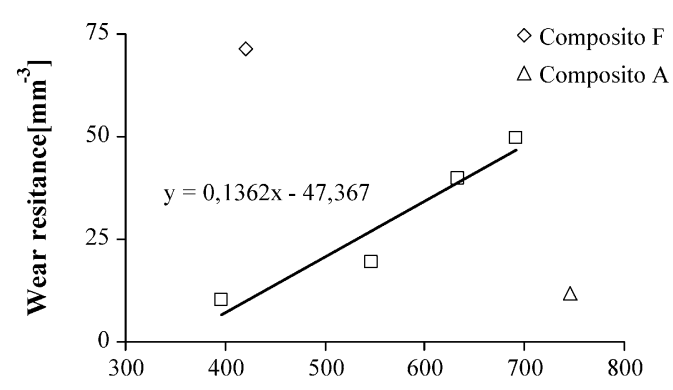

(b)

Hardness [MPa]

Fig. 6. Hardness vs. the wear resistance of the composites for the reciprocating test with: (a) abrasive slurry and (b) saliva.
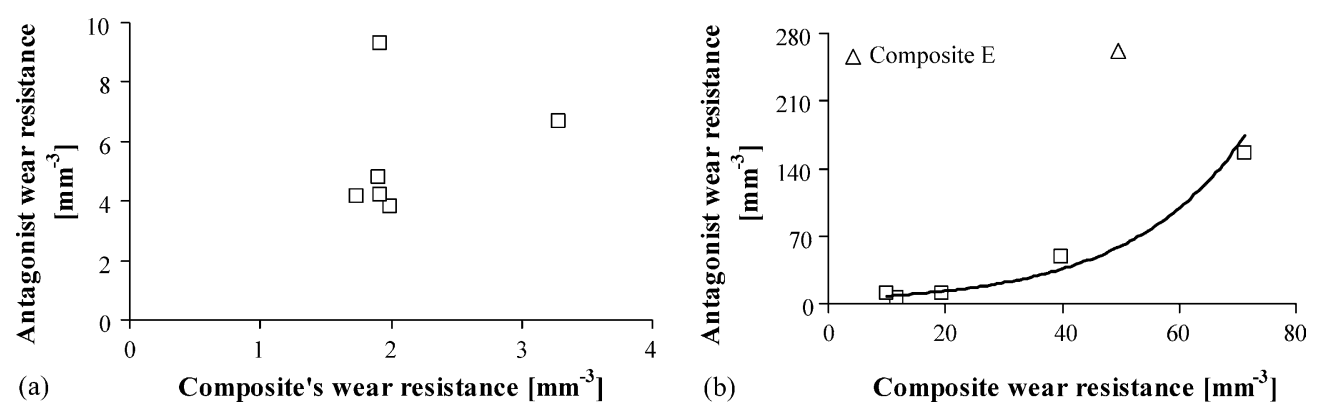

Fig. 7. Wear resistance of the composites vs. wear resistance of the antagonist in the reciprocating test with: (a) abrasive slurry and (b) saliva. 


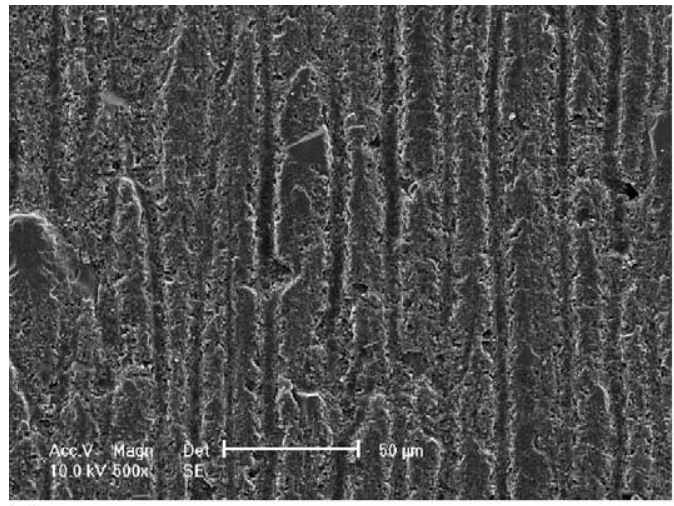

(a)

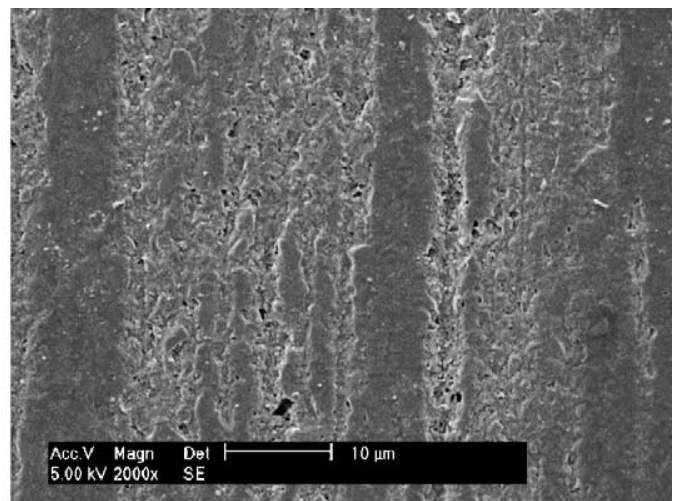

(b)

Fig. 8. Morphology of the composite specimens in the reciprocating test with: (a) abrasive (composite E) and (b) saliva (composite B).

\section{Conclusions}

The wear of dental restorative composites was investigated on reciprocating contacts against glass balls. The experimental study has been carried out with two environmental solutions: artificial saliva and aqueous abrasive slurry. This study made it possible to conclude that:

- On both restorative materials and antagonist glass, the wear volumes are greater for the tests with abrasive slurry than the ones with saliva;

- In the tests with abrasive slurry the amalgam performs better than any of the tested composites. However, in the tests with artificial saliva some composites show wear resistance similar to amalgam;

- Most of composite materials reveal a linear relation between the wear volume of restorative material and their hardness. This behavior was observed on both performed tests. However, the effect of hardness on the improvement of wear resistance is more marked in tests with saliva;

- For mild contact condition, which occurs for tests with artificial saliva, a big difference exists in the wear resistance of the various composite materials. However, for severe contact the wear volume of the amalgam is very small, when compared with the composites, which do not differ very much. An identical behavior was observed for the antagonist material;

- For the test with abrasive slurry, hard abrasive particles rest trapped between the contacting surfaces leading to large and deep scratches. In the wear tests with saliva, the surfaces present fewer scratches and the particles are worn along with matrix.

\section{Acknowledgement}

This study was supported by FCT - project POCTI/CTM/ $59858 / 2004$

\section{References}

[1] J.R. Condon, J.L. Ferracane, Evaluation of composite wear with a new multi-mode oral wear simulator, Dent. Mater. 12 (1996) 218-226.

[2] X. Hu, P.M. Marquis, A.C. Shortall, Two-body in vitro wear study of some current dental composites and amalgams, J. Prosthet. Dent. 82 (2) (1999) 214-220.

[3] S. Suzuki, S.H. Suzuki, C.F. Cox, Evaluating the antagonist wear of restorative materials when placed against human enamel, JADA 127 (1996) 74-80.

[4] J.R. Condon, J.L. Ferracane, In vitro wear of composite with varied cure filler level, and filler treatment, J. Dent. Restoration 76 (7) (1997) 1405-1411.

[5] R.W. Wassel, J.F. McCabe, A.W.G. Walls, Wear characteristics in a two-body wear test, Dent. Mater. 10 (1994) 269-274.

[6] A.J. Gee, R.N.B. Duinen, A. Wener, C.L. Davidson, Early and longterm wear of conventional and resin-modified glass ionomers, J. Dent. Restoration 75 (8) (1996) 1613-1619.

[7] H.H.K. Xu, J.B. Quinn, A.A. Giuseppetti, F.C. Eichmiller, E.E. Parry, G.E. Schumacher, Three-body wear of dental resin composites reinforced with silica-fused whiskers, Dent. Mater. 20 (2004) 220-227.

[8] B.S. Lim, J.L. Ferracane, J.R. Condon, J.D. Adey, Effect of filler fraction and filler surface treatment on wear of microfilled composites, Dent. Mater. 18 (2002) 1-11.

[9] D.E. Ruddell, M.M. Maloney, J.Y. Thompson, Effect of novel filler particles on the mechanical and wear properties of dental composites, Dent. Mater. 18 (2002) 72-80.

[10] J.W. Kim, K.T. Jang, S.H. Lee, C.C. Kim, S.H. Hahn, F.G. Godoy, Effect of curing method and curing time on the microhardness and wear of pit and fissure sealents, Dent. Mater. 18 (2002) 120-127.

[11] C. Zantner, A.M. Kielbassa, P. Martus, K.H. Kunzelmann, Sliding wear of 19 commercially available composites and compomers, Dent. Mater. 20 (2004) 277-285.

[12] V.S. Nagarajan, S. Jahanmir, V.P. Thompson, In vitro contact wear of dental composites, Dent. Mater. 20 (2004) 63-71.

[13] L.A. Flanders, J.B. Quinn, O.C. Wilson, I.K. Lloyd, Scratch hardness and chipping of dental ceramics under different environments, Dent. Mater. 19 (2003) 716-724.

[14] G. Williems, Multi Standard Criteria for the Selection of Potential Posterior Composites, Ph.D. Thesis, Katholieke Universiteit, Leuven, 1992, p. 76.

[15] J. Zheng, Z.R. Zhou, J. Zhang, H. Li, H.Y. Yu, On the friction and wear behaviour of human tooth enamel and dentin, Wear 225 (2003) 967-974.

[16] H. Li, Z.R. Zhou, Wear behavior of human teeth in dry and artificial saliva conditions, Wear 249 (2002) 980-984. 
[17] K. Kawai, K.F. Leinfelder, In vitro evaluation of OCA wear resistance of posterior composites, Dent. Mater. 11 (1995) 246-251.

[18] K.F. Leinfelder, S. Suzuki, In vitro wear device for determining posterior composite wear, JADA 130 (1999) 1347-1353.

[19] P.V. Antunes, A. Ramalho, Study of abrasive resistance of composites for dental restoration by ball-cratering, Wear 255 (2003) 990-998.
[20] D. Dowson, History of Tribology, Professional Engineering Publishing Limited, London, UK, 1998, p. 577.

[21] P.V. Antunes, A. Ramalho, Mechanical characterization of dental restorative composite materials, Mater. Sci. Forum 455-456 (2004) 393-397.

[22] J.F. Archard, Contact and rubbing of flat surfaces, J. Appl. Phys. 24 (1953) 981-988. 